\title{
REESCRITURAS DEL GÉNERO DEL TERROR DESDE LAS NUEVAS REALIDADES DIGITALES en CAM de DANIEL GOLDHABER
}

\author{
Rodrigo Bedoya Forno* \\ rbedoyaf@ulima.edu.pe \\ Universidad de Lima
}

Recibido: 15/4/2020 Aceptado: 09/7/2020

DOI: https://doi.org/10.26439/contratexto2020.n034.4868

Resumen. Este artículo busca explicar cómo la película Cam (2018) utiliza ciertos tópicos del género de terror (en particular, la figura del doppelgänger o doble) para, a partir de ellos, observar el cambio de las nuevas tecnologías digitales en la dinámica de nuestra cotidianidad. La película plantea una mirada sobre cómo las tecnologías digitales se han convertido en nuestras herramientas de trabajo y abastecimiento, a través de la historia de una camgirl cuya identidad es usurpada por una entidad, creando una dinámica de vida en la que no hay que desplazarse y todo se puede hacer con un clic. La cinta también le toma el pulso a las nuevas formas del cine de terror, estableciendo el internet como un espacio donde la violencia y el sexo se han convertido en herramientas para generar mayor interactividad entre los usuarios y permitir mejores ganancias. Pero no solo eso: Cam recurre a una serie de miedos contemporáneos ligados a las posibilidades de las nuevas tecnologías (el verse bloqueado de una cuenta o ser hackeado) para establecer un universo donde todas las explicaciones son posibles, y en las que resulta muy difícil determinar qué cosa es el enemigo.

Palabras clave: cine / terror / doppelgänger / digital / cine de género

\footnotetext{
* Magíster en Ciencia Política y Gobierno por la Pontificia Universidad Católica del Perú (véase https://orcid. org/0000-0002-3028-1128).
} 


\title{
REWRITING THE HORROR GENRE THROUGH NEW DIGITAL REALITIES IN CAM BY DANIEL GOLDHABER
}

\begin{abstract}
This article seeks to explain how the film Cam (2018) works with some themes of the horror genre (the doppelgänger or double, in particular) to show how the new digital technologies have changed the dynamics of our everyday life. The film offers, based on the story of a cam girl whose identity is taken by an unknown entity, a look on how digital technologies have become work and provision tools, creating a new life dynamic in which we do not need to move from one place to another and everything can be done with a click. The film also exposes the new forms of the horror genre, showing the Internet as a place where violence and sex have become tools to generate more interactivity with users, and allow better profits. But Cam also works with some contemporary fears that come with the new technologies (to be blocked from an account or the possibility of being hacked) to create a universe where all explanations are possible and where it is very hard to establish what is the enemy to beat.
\end{abstract}

Keywords: film studies / horror / doppelgänger / digital / genre films

\section{REESCRITA DO GÊNERO DE TERROR A PARTIR DAS NOVAS REALIDADES DIGITAIS EM CAM DE DANIEL GOLDHABER}

Resumo. Este artigo visa a explicar como o filme Cam (2018) utiliza determinados tópicos do gênero horror (em particular, a figura do doppelgänger, ou duplo) para, a partir deles, observar a mudança das novas tecnologias digitais na dinâmica de nosso cotidiano. 0 filme mostra como as tecnologias digitais se tornaram nossas ferramentas de fornecimento e de trabalho, através da história de uma camgirl cuja identidade é usurpada por uma entidade, criando uma dinâmica de vida na qual não há necessidade de se locomover e tudo pode ser feito com um clique. 0 filme também toma o pulso das novas formas do cinema de terror, estabelecendo a internet como um espaço no qual a violência e o sexo tornam-se ferramentas para gerar maior interatividade entre os usuários e permitir maiores lucros. Mas não é só isso: Cam usa uma série de medos contemporâneos ligados às possibilidades das novas tecnologias (ser bloqueado de uma conta ou ser hackeado) para estabelecer um universo em que todas as explicações são possíveis, e no qual é difícil estabelecer aquilo que é o inimigo.

Palavras-chave: Cinema / horror / doppelgänger / digital / cinema de gênero 


\section{INTRODUCCIÓN}

El cine de terror ha sabido representar, desde sus inicios, los miedos, dudas y represiones de su tiempo. Wood (2018) ya marcaba, de manera muy clara, cómo las películas del género representaban el conflicto entre marxismo y psicoanálisis, partiendo de la idea de las represiones personales y tensiones sociales que los monstruos, asesinos y demás seres del imaginario del horror simbolizaban. Por ese motivo, cuando los avances tecnológicos comenzaron a acelerarse, el cine no fue ajeno a preguntarse cómo esos cambios estaban teniendo un efecto en nuestra socialidad. El cine de David Cronenberg, por ejemplo, comienza, desde sus primeras películas, a entender la tecnología como una extensión del ser humano: una extensión inquietante, deforme, capaz de modificar nuestro cuerpo y nuestra mente. Cintas como Videodrome (1983) o Existenz (1999) exploran, justamente, las posibilidades de un cuerpo humano que se extiende y muta con los medios y las tecnologías, haciendo que estas se vuelvan parte de uno.

Sin embargo, hacia mediados de la última década del siglo xx, comenzó a plantearse un nuevo paradigma tecnológico (Castells, 1999) que cambió radicalmente la forma en la que nos relacionamos en sociedad y vamos definiendo nuestra identidad. Identificar las consecuencias que ha tenido la tecnología digital es un trabajo arduo que, probablemente, como señala Scolari (2008), recién se podrá terminar de realizar de manera precisa en unos años más, con cierta distancia. Sin embargo, ya nos encontramos en medio de la vorágine que lo digital ha traído: nuestras relaciones afectivas, personales y sociales se han modificado, la manera en la que comunicamos e investigamos, en la que obtenemos información y vivimos nuestros tiempos de ocio no son las mismas que hace veinte años.

Estas nuevas formas que la comunicación digital ha hecho que surjan, así como una serie de beneficios y avances, nuevas dudas y angustias que se ven acrecentadas por el avance de las tecnologías a pasos agigantados, generan la sensación de que es imposible seguirles el paso. El cine de terror, por ese motivo, no ha perdido la oportunidad de explorar esos miedos y dudas que provoca el nuevo mundo en el que estamos inmersos.

Cam (2018) de Daniel Goldhaber es un exitoso intento de hablar de los medios contemporáneos con relación a lo digital a través del cine de terror. El filme, basado en la experiencia de la coguionista Isa Mazzei, narra la historia de Alice Ackerman, conocida en el mundo virtual como Lola Lola (de aquí en adelante, Lola). Ella trabaja como camgirl, haciendo espectáculos eróticos por internet. Su obsesión es escalar posiciones en el ranking de la página web donde aloja su espectáculo, tratando de ser más audaz para generar más vistas.

El éxito de la protagonista es rotundo: ha podido hacerse una vida totalmente independiente gracias a sus espectáculos: la compra de una casa, la disposición de sus 
tiempos y el éxito económico nos son revelados desde el saque. Y para ella nada parece ser suficiente: lo único que está en su cabeza es seguir subiendo en el ranking de la página web en la que trabaja, ser cada vez más popular. El gran problema es que esa vida que ha desarrollado en internet no la comparte con su madre: la vida familiar es una cosa y la vida virtual, otra. La situación, sin embargo, parece estar bajo control.

Todo comenzará a cambiar, sin embargo, cuando, de la nada, alguien (o algo) se apropia de su cuenta. La persona o el ente que aparece en la imagen es exactamente igual a ella: mismo espacio, mismos objetos, misma voz, mismo rostro. Es una doble total de Lola, con el agregado de que se atreve a hacer una serie de actos eróticos que la Lola real no haría. Asustada por la situación, va a la empresa donde trabaja, pero sus compañeras (otras camgirls como ella) no le prestan mucha atención, pensando que se trata de un caso de hackeo de la cuenta. Al llamar al servicio técnico, se da con la sorpresa de que no puede acceder a su cuenta: su doble la ha tomado de manera definitiva.

Desesperada, decide llamar a la policía, pero el encuentro es inútil y hasta es acosada por uno de los agentes. Dándose cuenta de que está totalmente sola y de que su doble está llegando a extremos cada vez más gráficos en sus espectáculos, resuelve investigar un poco más; poco a poco descubre que hay un ente que ronda por la web y que toma las cuentas de camgirls populares, las cuales terminan muertas. El ente toma la forma de esas chicas, haciéndose pasar por ellas, y eventualmente las lleva a la muerte.

Decidida a acabar con la situación, Lola se crea una cuenta y confronta a su doble a un juego: la persona que se haga más daño físico tiene que hacer lo que la otra quiera. La Lola real gana, y le pide a su doble que le dé su contraseña. La doble lo hace, lo que permite a la protagonista recuperar su cuenta y desactivarla, poniéndole fin a su pesadilla.

Lo interesante de la propuesta de la película se expresa en la apropiación de elementos netamente genéricos, propios del cine de terror, para explotar las aristas que generan más incertidumbre y ansiedad sobre las maneras en que los nuevos medios digitales han cambiado nuestra vida. Cam toma ciertas realidades virtuales (el hacking, la deep web, la clonación de tarjetas de crédito, la usurpación de cuentas) y las moldea a partir de las convenciones del género del horror, generando una hibridación que no es otra cosa que la representación de los miedos que tenemos, como sociedad, sobre internet: miedos que se centran en el lado más oscuro y ambiguo de la red.

Este artículo busca analizar cómo la película va estableciendo una lectura de la nueva normalidad digital sobre la base de ciertas convenciones del cine de terror. Para eso, se comenzará aterrizando ciertas ideas generales sobre este género cinematográfico y, en particular, sobre uno de sus conceptos más icónicos: el doble o doppelgänger. Después, se examinará la nueva cotidianidad que plantea la película, una cotidianidad que incluye el mundo digital, para después ver cómo esa normalidad se va, poco a poco, volviendo cada vez más sombría de acuerdo con otras convenciones del terror actual, 
como la violencia y la aparición de un nuevo monstruo con características muy particulares: el monstruo digital.

\section{MARCO TEÓRICO: LAS CONVENCIONES DEL TERROR Y LA PRESENCIA DEL DOPPELGÄNGER EN CAM}

Cam se inscribe, de manera directa, dentro de la vertiente genérica del cine de terror, definida por Bordwell (2003) a partir de un elemento en particular: "[...] por su intencional efecto emocional sobre el público. La película de terror busca sobresaltar, causar repugnancia, en una palabra: aterrorizar. Este impulso es lo que forma las otras convenciones del género" (p. 103). Precisamente, el fin de la película de Goldhaber es generar un sentimiento de inquietud constante en el espectador, un sentimiento que se basa en la situación que vive Lola, pues, de pronto, su tranquilidad se ve trastocada por alguien o algo que se hace pasar por ella para el mundo a través de su cuenta de video.

Bordwell (2003) establece que eso que nos aterroriza es un monstruo. "En el filme de terror, el monstruo constituye una peligrosa alteración de la naturaleza, es decir, una transgresión de nuestro sentido común" (p. 103). ¿Qué explica que alguien, o algo, se esté haciendo pasar por Lola, viéndose exactamente como ella, sonando como ella, haciendo los mismos gestos que ella? No hay nada dentro del sentido común que lo pueda explicar. Y es por eso que Cam es la historia de Lola tratando de resolver ese misterio: ¿qué es aquello que ha usurpado su cuenta y tomado su imagen? ¿Es humano o algo sobrenatural? ¿Qué se puede hacer para detenerlo? La incertidumbre de la situación y los riesgos que corre la protagonista para resolver el misterio, y hacer que todo vuelva a una situación de normalidad (o al sentido común, como lo define Bordwell), son los motores que causan la tensión y el efecto emocional en el espectador.

Otro de los autores importantes que han hablado del cine de terror es Román Gubern. En el libro Las raíces del miedo. Antropología del cine de terror (Gubern y Prat, 1979), explica que el auge del terror como género cinematográfico se ha dado en momentos de amplia incertidumbre social: los primeros monstruos de Hollywood, el expresionismo alemán o el cine de terror estadounidense de los años setenta coincidieron con la Gran Depresión, la crisis de la República de Weimar, y la crisis generada por la guerra de Vietnam, el escándalo Watergate y la crisis del petróleo. Esta idea puede tranquilamente asociarse al universo que plantea Cam: el mundo de cambio de lo analógico a lo digital genera una serie de ansiedades tanto en las personas que no tienen las capacidades mediáticas para ese cambio como en aquellos que las tienen. El hecho de que nuestra vida cotidiana esté invadida por la tecnología digital (que usamos para trabajar, para distraernos y para una serie de actividades necesarias en nuestro día a día) sin duda plantea preguntas sobre los peligros y los límites de ese mundo digital que nunca terminamos de dominar del todo. 
En la misma línea encontramos a Christine Gledhill, quien propone una explicación psicosociológica del género, sobre cómo este ha conseguido trasladar a la pantalla una serie de miedos muy humanos. Parafraseando a la autora, ella señala que, después de la Segunda Guerra Mundial, los orígenes del terror han respondido menos a causas sobrenaturales, y se centran más en el hombre como base del miedo. Asimismo, considera que, incluso cuando el miedo tiene orígenes sobrenaturales, estos representan conflictos humanos y sociales (Gledhill, 1999), muy en consonancia con los que señala Gubern.

Uno de los grandes temas del cine de terror tiene que ver con la idea del otro. La entidad que viene a romper la normalidad es algo distinto a nosotros y, además, es exactamente lo opuesto a los valores encarnados por el protagonista. En el cine de terror, los héroes suelen ser personas de vidas relativamente tranquilas, que se guían por la razón y la cotidianidad; la monstruosidad, por el contrario, representa justamente todo aquello que va contra la razón, contra la normalidad: todo aquello que es visto con desconfianza, con incertidumbre, como lo que escapa a las normas.

Cam se enmarca en una tradición importante con relación a esta idea del otro: un otro que es igual a mí, que se ve como yo. Wood (2018) explica esta idea, estableciendo cómo ese otro se puede ver representado.

La relación tiene una forma particular: la figura del doppelgänger, alter ego o doble, una figura que ha aparecido constantemente en la cultura occidental, especialmente en los últimos cien años. Es el locus classicus en Dr. Jekyll and Mr. Hyde, donde la normalidad y el monstruo son dos aspectos de la misma persona. (p. 84)'

Lo que Lola y todos sus seguidores ven en la pantalla (y, en consecuencia, los espectadores) es un doble, algo que se ve igual que ella y que es capaz de hacer poses e insinuaciones sexuales que ella no se atrevía a hacer. El doble de Lola representa una versión mucho más audaz que ella: está las 24 horas al frente de la cámara, realiza poses y actos que Lola censura, no tiene ningún tipo de límite. Gracias a eso este doble consigue, de manera más efectiva, lo que Lola buscaba: tener gran número de seguidores e ir subiendo en el ranking de los canales más vistos en la página web donde trabaja. De esta manera, Cam es una película de terror que se inserta en la tradición del doppelgänger, de aquel que se ve igual que la protagonista y que toma su identidad, siendo dos caras de la misma moneda.

De la vieja tradición gótica alemana viene el concepto de doppelgänger: el doble, una persona exactamente igual a nosotros, pero que viene a ser, al mismo tiempo, "la

1 La cita es una traducción libre del texto original: "The relationship has one privileged form: the figure of the doppelgänger, alter ego, or double, a figure that has recurred constantly in Western Culture, especially during the past hundred years. The locus classicus in Stevenson's Dr. Jekyll and Mr. Hyde, where normality and monster are two aspects of the same person" (Wood, 2018. p. 84). 
antítesis de nuestra identidad original" (Meehan, 2017, p. 10). Las secuelas que tiene la aparición de ese doble nunca son buenas: se trata de una amenaza, de algo que va a traer una serie de consecuencias negativas y, por qué no, fatales:

En la cultura celta, por ejemplo, el doble es referido como el fetch, un gemelo idéntico que se cuenta que aparece al momento de nuestra muerte, una especie de psicopompo que acompaña al alma a la otra vida. En la mitología nórdica, estos seres son conocidos a veces como vardogoers, dobles fantasmales que imitan las acciones de sus contrapartes con vida. (Meehan, 2017, p. 10)2

En Cam, la figura que aparece es la de un doble digital: una entidad cuya interacción solo se puede ver a través de una pantalla, y que pertenece al universo de internet. La película utiliza una figura mitológica, que aparece de manera recurrente en la literatura fantástica. Como ya hemos dicho, este doble es mucho más audaz que ella: hace cosas que no se atreve a hacer la Lola real, tanto sexuales como gráficas. Si el deseo de Lola es ser cada vez más popular, pero poniendo una serie de límites, a este doble digital los límites no le interesan: están para romperse.

Más allá de que el doppelgänger supone un augurio de muerte y que, por lo tanto, genera una angustia que potencia el terror, las consecuencias psicológicas de esta figura han sido analizadas. Meehan (2017) señala que existe toda una serie de implicancias freudianas de este doble, que es lo mismo que nosotros en cuanto a apariencia, pero totalmente distinto en actitud. Esta, acaso, sea la representación del deseo secreto de aquello que queremos ser.

Según Freud, el doble es una manifestación externalizada de los deseos y derivas reprimidas del ego, es decir, todo lo que es inaceptable para él. Él [Freud] relaciona el doble con la formación del superego, que proyecta estas represiones primitivas en el doble misterioso de una manera similar a la que los dioses de la antigüedad se transformaron en demonios después del colapso del mundo pagano. (Meehan, 2017, p. 11) $)^{3}$

Uno puede ver cómo esta reflexión calza perfecto con lo que representa el doble de Lola para ella: es una versión desatada de cualquier forma de censura, de represión,

2 La cita es una traducción libre del texto original: "In Celtic folklore, for instance, the double is referred to as the fetch, an identical twin that is said to appear at the moment of one's death, a kind of psychopomp that scorts the soul to the afterlife. In Norse mythology, these beings were sometimes known as vardogoers, ghostly doubles that mimic the doings of their living counterparts" (Meehan, 2017, p. 10).

3 La cita es una traducción libre del texto original: "According to Freud, the double is an externalized manifestation of the ego's repressed drives and desires, that is, everything that is unacceptable to it. He links the double to the formation of the superego, which projects these primitive repressions onto the uncanny double in a manner similar to the way that gods of antiquity were transformed into demons after the demise of the pagan world" (Meehan, 2017, p. 11). 
de aquello que la propia protagonista se había puesto como límites. Pero en este caso el doppelgänger manifiesta no solo los deseos sexuales o exhibicionistas, sino también la codicia, los deseos de la Lola real de ser la más popular, la más querida, la que no se detiene para encantar a su público cautivo.

Pero el doble de Lola no pertenece al mundo real: no estamos hablando de alguien de carne y hueso, ni siquiera de un fantasma o de una entidad sobrenatural que viene al mundo real: hablamos de una entidad que existe y se manifiesta en la web. Y qué mejor lugar que la web para justamente dejar de lado los tapujos y presentarse sin censuras, sin filtros, sin ningún tipo de control sobre lo que uno hace. Millones de videos e interacciones muestran el costado más descontrolado de los usuarios en un espectro que va desde videos sexuales hasta insultos racistas, xenófobos o misóginos. Ese costado libre, sin censuras, es una de las características del medio: la libertad de internet, combinada con el anonimato, son un derecho (Perceval, 2015).

Y esa libertad hace que, muchas veces, nuestras actitudes cambien cuando estamos al frente de una pantalla. Nos mostramos sin censuras, sin filtros, emocionados por la anarquía de internet. La figura del doppelgänger, en Cam, viene a ser la representación de ese costado reprimido que, desde una pantalla, sale a la luz. Y que, como le ocurre a Lola, muchas veces se sale de nuestro control.

\section{LAS DIFERENCIAS ENTRE LOS MUNDOS DIGITALES Y REALES EN CAM}

Para Waisbord (2019), la comunicación digital se ha convertido en "el aire que respiramos" (p. 78). No hay nada que se escape de la comunicación digital: las relaciones interpersonales, las dinámicas de trabajo, el tiempo de ocio; todo se ha visto afectado, de una u otra manera, a partir de las tecnologías digitales. Al respecto, el autor afirma:

No es simplemente la extensión de dinámicas preexistentes o un nuevo capítulo en la interacción histórica entre los medios y la sociedad. No se trata tan solo de sectores sociales específicos volviéndose más conscientes, adeptos y vulnerables a los sesgos de contenido de "los medios". Más bien, es una revolución total en las dinámicas de la interacción social. Es la reconstrucción de la vida social. Es la mediación de la vida social como un todo, un metaproceso que redefine la vida social. Representa la culminación de la creciente colonización de la vida social y la comunicación humana por parte de las tecnologías mediáticas. Todo sobre la vida social se vuelve mediado: identidades, trabajo, intimidad, relaciones sociales, privacidad, seguridad. (Waisbord, 2019, p. 81) ${ }^{4}$

4 La cita es una traducción libre del texto original: "It is not simply the extension of preceding dynamics or a new chapter in the historical interviewing of media and society. It is not just about specific social sectors turning more conscious, adept and vulnerable to the technological and content biases of 'the media'. Rather, it is a complete revolution in the dynamics of social interaction. It is 
Si uno parte de la premisa planteada por Waisbord, la tecnología digital ha afectado cada uno de los rincones de nuestra vida (y la vida de Lola, sin ninguna duda). Ella cuenta con una comunidad de fanáticos, quienes interactúan con ella en el videoroom que ha creado y donde muestra sus espectáculos sexuales. Gigle, Dragon, Tinker y Barney, entre otros, son solo algunos de los seudónimos de las personas que entran a observarla, a hacer pedidos eróticos y a darle monedas virtuales que ella cambia por dinero real.

Se observa, en esa dinámica, cómo todo ha sido afectado por la comunicación digital. Lola, a sus 20 años, ha podido independizarse gracias a este trabajo: cada pose o juego sexual es gratificado por los usuarios a través de dinero. Castells (1999) hablaba de "la individualización del trabajador en el proceso de trabajo" (p. 294). Gracias a la tecnología digital, las reglas laborales se han ido flexibilizando, permitiendo que se vayan creando redes interactivas que establecen nuevas dinámicas laborales, como lo es el trabajo en casa. Y el trabajo sexual no ha cambiado en ese aspecto: Lola decide usar su cuerpo como una herramienta de trabajo, justamente, desde su domicilio, en un espacio acondicionado por ella, manejando sus propios tiempos y estableciendo sus propias reglas.

Todas y cada una de las funciones que son afectadas por la tecnología digital describen directamente a Lola: maneja una identidad digital y otra con su familia (erótica en internet, y una chica común y corriente con su familia); puede realizar teletrabajo a las horas que lo desea en un espacio propio; recibe un sueldo por eso, conversa y mantiene relaciones más o menos cercanas con algunos de sus seguidores. Ella maneja y moldea su forma de ser, su identidad, su labor y sus intimidades a partir de las posibilidades que le da el mundo digital.

Esa nueva forma de trabajo se complementa con una serie de seguidores de la joven, y con los que interactúa de manera anónima a través de exactamente la misma herramienta: internet. Scolari (2008) plantea que "toda la comunicación mediatizada es digital" (p. 82). La digitalización permitió establecer un universo donde los bits reemplazan a todas las actividades que Lola puede hacer directamente en su computadora: la grabación, la transmisión, el diálogo con sus seguidores y la manera en que estos le pagan tienen todos una misma textualidad, que es la virtual.

Esa posibilidad de interactividad entre la creadora y los usuarios es lo que Perceval (2015) Llama la creación de otra familia. Se crea una comunidad que reemplaza a la familia, que hace que todos aquellos que están viendo a Lola en ese momento se hermanen, puedan conversar entre ellos, criticarse, hacer bromas o ponerse de acuerdo

the reconstruction of social life. It is about the mediation of social life as a whole, a meta-process that redefines social life. It represents the culmination of the increased colonization of social life and human communication by medias technologies. Everything about social life becomes mediated -identities, work, intimacy, social bonds, privacy, security" (Waisbord, 2019, p. 81). 
para pedirle algo particular a la camgirl. Esta comunidad se vuelve una especie de club, de espacio donde las personas que están conectadas tienen muchos más puntos en común que con las personas con las cuales hay contactos físicos; ellos viven en "mundos virtuales" (Perceval, 2015, p. 271).

Sin embargo, la película no establece la presencia de lo digital solamente en el trabajo o en la creación de una comunidad que interactúa tanto con Lola como con otros de sus miembros, sino que, además, está presente en todos y cada uno de los aspectos de la vida de la protagonista: si pide una pizza, lo hace a través de un aplicativo para pedido de comida; si se tiene que desplazar de su casa, lo hace a partir de las indicaciones de un aplicativo que le permite evitar el tráfico. La vida de Lola depende exclusivamente de la tecnología digital: para trabajar, para comer, para movilizarse, para ganar dinero. Ella ha creado una cibervida.

Una cibervida tan poderosa que es totalmente distinta a la vida que realiza con su familia real: solo su hermano sabe de su actividad como camgirl, pero su madre (que maneja un salón de belleza) desconoce totalmente lo que hace su hija. Lola no tiene amigas, y cada vez que algo parece aterrizarla en el mundo real, existe siempre una tensión. El momento en el que ella se reencuentra con una amiga de su colegio es un excelente ejemplo: mientras Lola ha conseguido cierta holgura económica por su cibertrabajo, su compañera debe esforzarse en un trabajo precario dentro de un centro comercial. Se muestra, entonces, al mundo virtual como un espacio próspero, en contraste con un mundo real lleno de carencias y de dificultades.

Aquí volvemos a una de las bases originales sobre las que se sustenta la película como cinta de terror: la idea del otro, que siempre está perturbando la cotidianidad de la protagonista. En este caso, hablamos de una otredad virtual: Lola ha conseguido crear una nueva figura, un yo virtual. Ese yo virtual le ha permitido ser una estrella, ser deseada y admirada por todos sus seguidores, y establecer una solvencia económica que probablemente no habría conseguido de otra forma. El otro amenazante, por tanto, es el mundo real, donde ella tiene que mantener la normalidad y las apariencias para poder pasar como una chica común y corriente. En el mundo virtual todo está permitido y las reglas se abren y se flexibilizan, mientras que, en el mundo real, la protagonista debe mantener las apariencias.

Por ese motivo, cada choque entre el mundo virtual y el mundo real resulta tenso, amenazante, como la posibilidad de que todos vean la verdadera identidad de Lola. No solo su familia y su amiga de colegio le recuerdan la precariedad de la vida real (que ella ha sorteado por su trabajo virtual), sino que los encuentros reales con dos de sus fanáticos resultan momentos de plena tensión: mientras que en el mundo virtual se muestran como personas amables, juguetonas y hasta preocupadas, en el mundo real son amenazantes, acosadoras; momentos de tensión en que la tranquilidad de la protagonista 
se ve amenazada por el otro, un otro que es definido básicamente en las diferencias y contrastes entre la realidad y la virtualidad.

De esta manera, así como la comunicación digital se ha introducido en todos los aspectos de nuestra vida, también lo ha hecho en una dimensión ligada al concepto de otredad: el otro se crea a partir de lo real y de lo virtual, incluso si hablamos de la misma persona. Así el terror se va creando en Cam sobre la base de un concepto del otro que se define por los mundos distintos que se generan gracias a la tecnología digital.

\section{EL TERROR CONTEMPORÁNEO EN CAM}

Hemos establecido que Cam utiliza un recurso relativamente conocido dentro de lo que es el cine de terror: la idea del otro (en este caso, el doppelgänger), que tiene rasgos iguales a la protagonista y usurpa su personalidad; no obstante, esta idea de otredad no solo está en la entidad que asume la cuenta de Lola, sino que también se encuentra en la diferencia entre el mundo virtual y el mundo real de la protagonista: en el virtual, mantiene una personalidad y una comunidad de personas que la admiran por lo que hace con su cuerpo, mientras que en el real siempre se desenvuelve en una realidad precaria, donde tiene que esconder su identidad y donde los encuentros físicos con personas (ya sean del pasado o algunos de sus fanáticos) son incómodos 0 , incluso, peligrosos.

El mundo virtual en el que Lola trabaja es un universo donde ella usa su cuerpo para hacer espectáculos eróticos y conseguir subir en el ranking de la página web en la que está alojada, mientras va recibiendo monedas virtuales que ella puede canjear después por dinero real. Sin embargo, la primera escena de la película nos muestra que el erotismo no es lo único con lo que juega la protagonista.

En efecto, en esa primera escena, mientras flirtea con sus seguidores mostrando vibradores y dándose nalgadas, Lola de pronto comienza a recibir mensajes de alguien que le pide que se suicide ante las cámaras. Asustada primero, comienza a desafiar a este seguidor hasta que, de pronto, saca un cuchillo y se corta la yugular. Todo, sin embargo, termina siendo una farsa: ella fingió su propio suicidio para poder conseguir cada vez más seguidores.

La muerte de Lola es todo lo explícita que se puede imaginar: la sangre sale a borbotones de su cuello mientras sus seguidores (y nosotros, los espectadores) no salimos de nuestro asombro. Cam, de esta manera, no tiene ningún reparo en mostrar una violencia que resulta bastante llamativa justamente por su naturalidad, por la manera franca y directa que elige el director para mostrárnosla. Esta primera escena (que marca el tono de la película en sí) es una representación de lo que Imbert (2019) llama una banalización del horror en el cine postmoderno. Para el autor, el horror se ha vuelto un asunto cotidiano, algo con lo que convivimos todos los días. Afirma: 
Hoy el horror se ha instalado en la representación cinematográfica. Se ha banalizado como objeto, y ello se debe a dos factores: primero, la trivialización de la violencia desde los noventa y, luego, la mayor familiaridad que establece una representación cada vez más cruda de la muerte y de la enfermedad, de las pulsiones y de las perversiones [...]. Eso deja paso a un cara a cara con el horror que puede crear malestar, pero ya no es rechazado como tabú. (Imbert, 2019, p. 348)

Estamos, pues, ante una forma de ver el horror que ya no tiene ningún tipo de filtro o de reparo, y que, más bien, hace de su frontalidad su apuesta, su forma de representación. Y pareciera que la propia Lola es consciente de eso al jugar con su suicidio en vivo: la mujer sabe que eso puede ser, más que algo reprensible, un motivador del morbo de sus seguidores. Para Imbert (2019), "[...] el sujeto se siente atraído por lo siniestro, por lo que no tiene origen ni fin" (p. 349). Y Lola lo sabe, aprovechando que estamos en un mundo en el cual la violencia se ha convertido en algo natural, que convive con nosotros y que incluso puede generar un placer extraño.

Esta idea de un horror normalizado, desacralizado, que se muestra como algo natural y que, además, puede provocar un placer morboso tiene que ver, en la película, con lo que nos ofrecen las tecnologías digitales. Ese universo sin límites, desregulado, en el cual se puede trabajar con una cámara y desde casa, va forjando una cultura del "todo vale", de la necesidad de obtener réditos a cualquier precio, ya sea simulando un suicidio o rompiendo ciertas reglas que la propia Lola se había impuesto.

Dos momentos ejemplifican de manera muy clara esta idea: el primero de ellos, cuando Lola llega a estar entre los primeros cincuenta lugares de la página web que la acoge. Al momento de hacerlo, se da cuenta de que hay otra chica, cuyo seudónimo es PrincessX, quien, en su cuenta, dice que se desnudará solo si Lola baja diez posiciones. El mundo en el que se desenvuelven estas camgirls es un entorno hostil, donde no existe ninguna forma de regulación y todo está permitido, incluso traicionar o jugar sucio contra alguien directamente.

No obstante, y justamente para recuperar ese espacio perdido, Lola decide tomar cartas en el asunto: hará un show en vivo con el Vibatron, un vibrador eléctrico de intenso poder. Lola va hasta donde queda la empresa que la acoge y realiza su espectáculo ahí, incluso cuando ella misma afirma no querer ir hasta el lugar (pues queda muy lejos de su casa) y que hacer eso sería muy extremo: el aparato es tan potente que puede dejarle secuelas en sus órganos sexuales.

El cuerpo en la película se convierte, de esta manera, en la herramienta de este mundo virtual donde, al no existir reglas ni regulaciones, se puede hacer básicamente cualquier cosa, incluso perjudicar a otra persona o llevar el cuerpo a límites insospechados, hasta donde la representación digital lo permita. El concepto de lo digital en Cam es el lugar donde todo se puede hacer, donde no existen reglas prefijadas y en donde hay 
que defenderse como sea del ataque, donde se puede llegar a extremos para conseguir las metas dispuestas. En el caso de Lola, su cuerpo deviene en esa herramienta, en esa arma que usa para poder competir en esta carrera donde no existen reglas. Es un cuerpo que se mueve entre extremos, donde el fetichismo se vuelve el motor para explotarlo (Imbert, 2019) y donde lo que importa es explotarlo, sacarle todo el jugo posible para poder conseguir los objetivos planteados por la protagonista.

Así el terror y el sexo se combinan en el universo digital de una forma única. Este mundo digital busca, en chicas como Lola, la explotación de una de las características de la representación que permite la falta de regulación y la posibilidad de crear de manera tan simple: una representación cruda, directa, que no tiene ningún problema en mostrar un cuello desangrándose o cómo un vibrador electrónico lleva al límite la capacidad de resistencia sexual de la protagonista. La desensibilización de la violencia en la forma en que se exhibe a través de internet hace que esta ya no sea censurable, sino deseada tanto para los espectadores que observan el espectáculo de Lola como para ella misma, que encuentra en esas formas de representación una manera de alcanzar sus objetivos. El "todo vale" se convierte, entonces, en un espacio digital donde se explota la normalidad de la violencia, tan propia de las formas de las imágenes hoy en día.

\section{EL DOBLE COMO EXTREMO EN CAM}

Hemos señalado que Cam basa su premisa, como película de terror, en función de la idea del otro; una idea que se sustenta en una otredad digital, que se establece en la dicotomía mundo real/mundo digital: los dos mundos en los que vive la protagonista. Esta visión del terror también se funda en su representación de la violencia y del sexo: directa, sin ningún tipo de miramientos, como si fuera algo que formara parte de la normalidad dentro de las formas de representación. Lola pone su cámara y se corta la yugular o usa un vibrador de mucha potencia sabiendo que, lejos de generar repulsión, ahora ya es parte de lo que se espera que se haga para conseguir más seguidores y ganar más monedas. Es así como Cam nos va mostrando un mundo donde la violencia y su representación ya no tienen ninguna forma de censura o contención, y más bien son armas que usa la protagonista para afirmar su éxito.

Como hemos señalado, la idea de otredad en la película se centra, en un primer nivel, en el mundo real contrastado con el mundo virtual de Lola, pero el tema del otro también se ve en la entidad que toma su cuenta y comienza a hacerse pasar por ella.

Esta doble de Lola ha tomado absolutamente todos los rasgos de la protagonista, pero con una serie de características particulares: por un lado, nunca duerme y puede estar todo el tiempo conectada, en contacto con sus seguidores, ya sea a través de la web grupal como en chats privados. Además, hace cosas que la propia Lola se había impuesto que no haría: si Lola había puesto ciertos límites a sus escarceos sexuales, el doble no 
tiene ningún problema en romperlos, haciendo espectáculos en lugares públicos (como una biblioteca) y hasta participando en un espectáculo lésbico con otra chica. Si Lola juega a cortarse la yugular, este nuevo personaje no tiene ningún problema en pegarse un tiro en la boca para beneplácito de sus espectadores.

Si la propia Lola entiende que la violencia y el morbo son elementos que, dentro de su comunidad digital, se convierten en valores que le dan beneficios, lo que muestra el doble es una Lola potenciada, mucho más ambiciosa, que utiliza precisamente esa falta de límites y reglas dentro de la web para conseguir más seguidores. Es así como rápidamente la nueva Lola va subiendo puestos en el ranking de la página web que la acoge.

Por ese motivo, la única forma de eliminar a este ser es jugando su propio juego: si el doble es extremo, pues a Lola no le queda otra que ser doblemente extrema. Cam nos presenta un universo donde internet es el espacio de la complacencia: uno hace aquello que genere más réditos, lo que plazca a aquel que nos ve, que explote, justamente, esa normalización de la violencia y del sexo; una normalización que hace que aquellos que observan a la protagonista a través de su chatroom le pidan cosas más morbosas, más violentas, más extremas. Uno tiene que hacer lo que el observador pide. Y de eso se da cuenta Lola: debe ganarle a su doble con esas reglas de juego. Esta competencia es lo que le permite, finalmente, recuperar su cuenta y poder ponerle fin a la pesadilla.

En el espacio desregularizado y anárquico que es internet, Lola entiende que la única manera de derrotar a su doble, que aparentemente solo piensa en qué tan popular puede ser, es siendo más atrevida que ella, más violenta que ella. Internet se convierte en un espacio donde la violencia se vuelve una herramienta de competencia: la clave para vencer en un concurso de popularidad. La representación de la violencia en internet no solo se ha desacralizado: se ha vuelto en algo deseable, aquello que nos da el diferenciador para ganar más clics, más dinero, más poder.

\section{EL DOBLE COMO REPRESENTACIÓN DE LO DIGITAL EN CAM: LA APARICIÓN DEL MONSTRUO DIGITAL}

Hemos establecido que Cam muestra un mundo que, basado en las convenciones del cine de terror, plantea una mezcla entre el concepto del otro y la representación de la violencia en tiempos posmodernos: la violencia se ha desacralizado y se convierte en moneda corriente, en algo que sirve para generar más adeptos y ser más popular en la red. Eso es lo que le permite a Lola, finalmente, derrotar a su doble: internet es el universo del "todo vale", donde la única regla es que no hay reglas, y decide usar eso a su favor para acabar con aquello que la ha estado aterrorizando todo este tiempo. 
Sin embargo, hay dentro de todo esto algo que falta establecer: ¿cuál es la procedencia de ese doble? ¿Qué cosa es lo que toma la imagen de Lola, que es capaz de mostrar a través de su cámara, su casa, su cuarto, sus fotos? ¿Cómo es posible que ese doble haya podido recrear virtualmente el universo de Lola, que haya podido copiar exactamente todos los detalles de su mundo real?

Como ya se ha establecido anteriormente, el cine de terror consiste en cómo la cotidianidad se quiebra por la aparición de un monstruo que comienza a atemorizar a los protagonistas, lo que genera situaciones emocionalmente intensas para el espectador (Bordwell, 2003). Sin embargo, generalmente se establece qué cosa es ese monstruo, de dónde viene y cuáles son sus características. Wood (2018) señala, por ejemplo, una serie de motivos recurrentes del cine de terror a partir de los años sesenta: el monstruo humano o psicópata, la revancha de la naturaleza, satanismo o posesión diabólica, el niño terrible y el canibalismo.

Uno puede establecer, en las películas de terror, que aquello que se configura como el elemento disruptor en la historia sea un ente sobrenatural (un fantasma, un demonio, un monstruo), natural (un asesino) o una mezcla de ambos (animales que, sin explicación, comienzan a atacar personas; una persona poseída). Por ese motivo, resulta interesante preguntarse en qué categoría se encuentra el doppelgänger de Cam. ¿Es un fantasma que toma la forma de quien quiera? ¿Es un demonio que se esconde en las computadoras? ¿Es una entidad sobrenatural que encuentra en la web la mejor forma de atacar?

Todas estas preguntas no encuentran respuesta en la película: nunca sabemos cuál es el origen de aquello que toma la forma de Lola. No existe nada en la película que nos permita establecer de dónde ha surgido este monstruo, qué cosa lo ha creado, a qué tipo de amenaza la protagonista se está enfrentando. Y lo que cabe preguntarse es si acaso este nuevo tipo de monstruo no responde a una amenaza que tiene las características de lo que ofrece el mundo virtual, que sabe moverse y mutarse sinuosamente dentro de un universo en el que todo se mezcla y en donde no hay certezas. Internet es un mundo donde todo converge, donde distintos medios se han fusionado para producir algo que tiene mucho de nuevo, pero para crear esa dimensión novedosa se ha nutrido, justamente, de todos los otros medios que han existido antes (Scolari, 2008). Y, por qué no, de todos nuestros miedos también.

Una de las características de los medios digitales es su capacidad de convergencia (Scolari, 2008). Para este autor, definir tal concepto resulta complicado, puesto que uno puede abordar este término desde distintos ángulos: el empresarial, el tecnológico, el profesional y el comunicativo, entre otros. Sin embargo, uno puede, dentro de la complejidad, tratar de establecer la convergencia como la capacidad que ha tenido internet de usar todos los medios anteriores a su aparición (lo impreso, la televisión, el video, 
el audio, el telégrafo, las conexiones telefónicas y otras más) para crear una dinámica propia, que se nutre de estos medios y de otros. En internet, todos los medios convergen para forjar una nueva dinámica para el usuario, el cual, de acuerdo con el autor, genera una serie de espacios indefinidos. Según Scolari (2008):

¿Qué sucede cuando la convergencia de lenguajes y medios supera la fase inicial? Las diferentes retóricas abandonan sus respectivas ventanas en la pantalla y se contaminan entre sí. La multimedialidad o la convergencia retórica dejan de ser algo más que una suma de medios en una única pantalla: los lenguajes comienzan a interactuar entre sí y emergen espacios híbridos que pueden dar origen a nuevas formas de comunicación. Esta idea que estamos delineando nos aleja de cualquier planteamiento extincionista. Cuando nace un nuevo medio o lenguaje, las formas anteriores de comunicación no desaparecen como los dinosaurios. (p. 104)

La clave de Cam radica precisamente en meterse en ese espacio híbrido, en explorar un lugar en el cual no podemos establecer con certeza qué cosa es aquello que está acabando con la tranquilidad de Lola. Sabemos que es algo que no tiene manifestación en el mundo real, sino que simplemente la aterroriza en el mundo virtual; mundo virtual que se había convertido en una especie de espacio seguro para la protagonista, donde había hecho su fama y su fortuna.

Pero también resulta interesante notar cuáles son las capacidades de ese monstruo, que son absolutamente las mismas que cualquier persona puede tener al momento de usar la web: lo que vemos es un cuerpo grabado por una cámara. Mientras que en el cine de terror tradicional aquello que ataca la normalidad resulta tener algún poder especial, aquí lo que hace el doppelgänger es usar las mismas técnicas que cualquier persona podría usar para convertirse en una camgirl y subir contenido a internet. En un mundo donde la red permite que todos seamos creadores (Perceval, 2015), la estrategia de este monstruo es usar esas herramientas para generar inquietud. Si los fantasmas tiran muebles y cierran puertas, o los vampiros chupan sangre, pues lo que necesita el otro de Lola es simplemente audio, video y una contraseña de internet.

Estamos, pues, ante un monstruo en el que convergen todas las características de internet y que, a su vez, se desenvuelve en un medio que se basa en esa convergencia. Un monstruo que es capaz de tomar una cuenta, cambiar una contraseña, usurpar un espacio y, a través de una cámara, adoptar la forma y la figura de Lola. Aquí entra a tallar otro concepto del que habla Scolari (2008): el de "remedación" (p. 105). La remedación es, de acuerdo con el autor (quien, a su vez, cita a Richard Grusin), "la contaminación entre viejos y nuevos medios" (p. 105). Es decir, estamos ante la capacidad que tiene internet de tomar elementos de otros medios y copiarlos, de tal manera que termina siendo un enorme repositorio de las características de otros medios. 
El doppelgänger de Lola es, pues, un claro remedo de la misma Lola: no solo se ve igual que ella, sino que utiliza exactamente sus mismas herramientas de trabajo (una cámara, una cuenta) dentro del universo digital. Pero no solo eso: también remeda sus aspiraciones, sus deseos, su afán de protagonismo. Lo único que parece mover al monstruo es tener más seguidores, conseguir que su chatroom sea cada vez más popular. La obsesión de Lola, desde el inicio de la película, es seguir subiendo en el ranking de la web, ser cada vez más popular con sus seguidores, tener cada vez más y más reconocimiento. El otro virtual de Lola remeda ese deseo y no para hasta hacerlo realidad, rompiendo las propias reglas que la protagonista se había puesto. El mundo desregulado de internet propicia esa competencia y, de pronto, el monstruo virtual que aparece se contamina de ese afán.

Pero el concepto de remedación también puede verse en el contenido que va creando este otro para generar más vistas y subir en el ranking. No solo estamos ante algo que usa las mismas herramientas que la protagonista, que remeda sus formas de crear contenido en el mundo virtual y que es capaz de tomar sus deseos y llevarlos hasta límites insospechados, todo sea por ser más popular. Estamos ante una entidad virtual que aprovecha, justamente, la desensibilización que existe ante la violencia y el horror en estos tiempos para poder avanzar en sus objetivos. Como afirma Imbert (2019):

Hoy el cine ha franqueado un paso más: el horror ha contagiado al propio individuo y se ha extendido a las relaciones humanas. El sujeto pierde la conciencia del horror porque este se ha desvinculado de todo sentir, hasta del placer perverso y del uso lúdico. Es intrínseco, es decir, sin consciencia de las consecuencias, del daño que puede hacer, desgajado del otro como ser sensible. Estamos ante una desensibilización total del horror. (p. 419)

Si la película comienza con Lola cortándose la yugular, en un espectáculo falso, armado para generar mayor interacción con sus seguidores, el doble de Lola va un paso más allá y se dispara en la boca para provocar exactamente lo mismo. Ambos gestos responden a esa desensibilización absoluta del horror: hoy en día el horror por internet es un disparador de adrenalina hecho para generar mayores interacciones. Y Cam usa esa característica para tomarle el pulso al horror posmoderno, a cómo entendemos la representación de la violencia, ya no necesariamente como algo que altera o perturba, sino como algo que se espera dentro del mundo de internet.

De esta manera, lo que hace el doble de Lola es tomar esa desacralización de la violencia y llevarla un poco más allá, remedando su uso, entendiendo que eso es lo necesario para poder tener mayores interacciones. Si esta entidad remedaba a Lola en sus formas y en sus aspiraciones, también toma representaciones y sensibilidades con relación al horror contemporáneo y las reproduce no como un mecanismo de sensibilización, sino como un motor de morbo para conseguir mayor popularidad; algo que se encuentra 
ligado a representaciones del horror mucho más directas e insensibles. Si el doble de Lola era un remedador de medios, también lo es de miedos.

\section{LO DIGITAL Y EL QUIEBRE DE LA NUEVA NORMALIDAD EN CAM}

Esta idea de un espacio híbrido, poco claro, se une a la idea de internet como espacio anárquico, donde todos pueden crear de acuerdo con su capacidad y dominio de las herramientas. Como explica Perceval (2015), "la capacidad de creación es algo personal, la posibilidad de edición es simplemente una habilidad adquirida y adquirible mediante la alfabetización digital" (p. 275). Y, ciertamente, lo interesante de ese nuevo espacio es que, como cualquiera puede crear, cualquiera puede acceder a información personal, tomar tarjetas de crédito, hacerse pasar por alguien más. El hacking se ha convertido en moneda corriente, puesto que cualquiera puede tener la capacidad de acceder a espacios virtuales con el conocimiento necesario: un conocimiento que ya no es precisamente especializado, sino que puede estar a un clic de distancia, facilitando el acceso a archivos personales y a información confidencial y personal (Perceval, 2015).

Por ese motivo, Lola nunca termina de estar segura de qué cosa es aquello que toma su imagen y se vuelve su doble. Y no lo está porque, dentro del mundo virtual, cualquier cosa es posible relativamente: las explicaciones son mucho menos fijas, más inciertas. Esto hace que Cam nos muestre un cambio con relación al terror más ortodoxo, pues, por lo general, las películas del género buscan esclarecer, tarde o temprano, que aquello que ataca la tranquilidad es una entidad de un tipo específico, ya sea natural o sobrenatural; sabemos que aquello que genera el conflicto tiene alguna naturaleza clara.

En Cam, todo el tiempo se mantienen las dudas, puesto que la propia naturaleza del enemigo digital hace que esto ocurra: la hibridez y la configuración de lo digital permite, con un poco de conocimiento, entrar en caminos relativamente oscuros (lo que vuelve más difícil identificar al enemigo). Las distintas explicaciones que encuentran sus compañeras de trabajo cuando Lola les muestra a su doble son la prueba de ello: "Quizá sea un show repetido", dice una. "Claro, nosotros le damos a la página web el derecho a los videos que grabamos", dice otra. "Quizá sea una falla técnica", es otra explicación que se escucha. "Bienvenida a internet, las cuentas se pueden hackear", le comenta otra al ver la situación. Ninguna parece alterada, asustada, aterrada. La nueva normalidad es aceptar que aquello que no se puede explicar es posible.

Las explicaciones de las compañeras de trabajo de la protagonista expresan una característica de los tiempos digitales: básicamente, el funcionamiento de internet se ha vuelto lo normal, lo cotidiano, aquello que damos por hecho mientras que lo incierto, por otro lado, forma parte de esa idea de dar por sentadas las cosas: el mundo de internet admite todo el tiempo la posibilidad de un hackeo, de una duplicación de identidad, de que alguien ingrese a nuestra información confidencial, a nuestra cuenta, en resumen, 
de que alguien invada nuestro mundo virtual. Pocas películas como Cam han mostrado cómo las tecnologías digitales han reconfigurado nuestra vida: los personajes dan por sentadas ciertas cosas que implican un alto grado de incertidumbre. La posibilidad de que algo salga mal cuando uno crea una realidad virtual es algo que está dentro de lo cotidiano, dentro de aquello que puede pasar de manera relativamente frecuente conformando así una nueva normalidad.

Por ese motivo, el monstruo virtual que ataca la tranquilidad de Lola es doblemente peligroso: no solo es uno que utiliza las mismas armas de la protagonista (una cámara, la imagen, el sonido), sino que su ataque (el hackear una cuenta, el tomar una identidad) se encuentra entre los riesgos comunes de internet, que pueden tener una explicación común: desde una falla técnica hasta un hackeo básico. Acaso Cam, creando ese monstruo virtual, es una alegoría de las posibilidades que nos ofrece internet: todos somos potenciales creadores, como diría Perceval, y eso hace que todos salgamos del mismo barro: los que lo usamos para el entretenimiento, los que lo usamos para el trabajo y los que lo usamos para las fechorías. Todos poseemos las mismas armas y todos somos capaces de lo mejor y de lo peor, sin posibilidad de establecer diferencias. El desconcierto de Lola es, pues, el resultado de este mundo donde todos partimos con las mismas capacidades para el bien y para el mal, y en donde cualquier anomalía puede ser explicada de alguna u otra forma.

Y es por eso que vale la pena volver a uno de los puntos básicos del cine de terror: la idea de una normalidad que se quiebra. Wood (2018) habla de "una simple y obvia fórmula básica para el cine de terror: la normalidad es amenazada por el monstruo" (p. 83). Esa cotidianidad que se rompe, dentro del universo de Cam, es una normalidad establecida sobre la base de cómo lo digital penetra y contamina nuestras vidas: para Lola, lo normal es usar una cámara web para trabajar con su cuerpo, jugando y coqueteando con una comunidad virtual que, a cambio de sus espectáculos, le ofrece una remuneración. Sin embargo, la normalidad también es pedir comida por internet, desplazarse con la ayuda de un aplicativo, comprar a través de la web. En el mundo de la protagonista, todo se hace a partir de lo virtual.

Por eso, cuando de pronto surge este doble que parece tomar su identidad, esa normalidad se ve trastocada en varios niveles. En un primer nivel, evidentemente, la inquietud surge de que algo o alguien ha tomado la imagen de la protagonista. ¿Es un farsante? ¿Es la repetición de un show viejo? ¿Es una falla técnica? ¿Es un hacker? ¿Es algo sobrenatural? Dentro de esa normalidad digital, cualquiera de esas respuestas suena relativamente posible: lo que en una película de terror estaría contestado desde un principio (o, por lo menos, desde el momento en que se determina la naturaleza de la amenaza), aquí resulta mucho menos certero y, por lo mismo, extremadamente inquietante. La indefinición del monstruo es un motivo de incertidumbre constante: Lola no sabe a qué se está enfrentando. 
El ataque de este monstruo digital, que no tiene una forma física concreta y cuya explicación puede ser cualquier cosa ( $\mathrm{y}$, por lo tanto, resulta inidentificable), se remite a una serie de conceptos del terror contemporáneo. Imbert (2010) plantea que hoy los monstruos ya no son concretos, sino que son inmanentes e inherentes a la naturaleza. Tal hecho tiene que ver con lo siniestro: "El recuerdo de algo inconcreto [...], atemporal [...], deliberadamente descontextualizado" (p. 482). Esa atemporalidad y descontextualización calzan muy bien con la idea de un monstruo como el que ataca a Lola: indeterminado, que puede ser cualquier cosa, que usa las mismas armas que la protagonista. Lo siniestro se encarna en la monstruosidad del doble, en esa incapacidad que hay para definirlo.

Esa incapacidad para definirlo puede ser una representación de lo que es internet: ya hemos establecido que se trata de un espacio anárquico, que no tiene reglas claras y donde básicamente todo es permitido. Perceval (2015) habla del hacking, del cracking y el poco respeto a los derechos de autor, algo que llegó para quedarse con la aparición de internet. Pero el software libre, en un principio el dolor de cabeza de los productores audiovisuales y musicales, no fue la única forma criminal que se instaló en la web. Dice Perceval (2015):

Por otro lado, la exposición de opiniones libres en la red, una de sus mejores características, permite asimismo la canalización de sentimientos xenófobos y excluyentes, de rumores infundados, de insultos y todo tipo de agresiones verbales. Internet no ofrece herramientas claras en este sentido. Solo la posibilidad de desmontar los argumentos xenófobos y excluyentes y la expulsión de los que no respetan las mínimas normas de cortesía de foros y chats. Se necesita una mayor interacción para neutralizar a estos grupos que se distinguen por su inhibición, su violencia simbólica (ocupar espacios mediante el insulto y la constante agresión verbal), su estrategia intoxicadora [...]. (p. 279)

El monstruo digital al que se enfrenta la protagonista tiene, de esta manera, una serie de características que lo hacen un monstruo de nuestros tiempos: indeterminado, imposible de identificar, pero que, además, cumple con una serie de rasgos típicos de lo que es internet: un espacio anárquico, donde no existen reglas, donde la violencia está normalizada y resulta difícil frenarla.

Por eso, se puede establecer que el doble de Lola es un monstruo que representa todos los miedos que genera internet: el miedo a la invasión, el miedo a la usurpación de la identidad, el miedo a la agresión, el miedo a la violencia irracional que puede nacer del tuit de un trol o de una imagen. Y el miedo de no poder determinar de dónde viene esa agresión, de que la impunidad por la falta (o delito) cometido quedará para siempre, porque es imposible identificar quién la hizo y con qué herramientas.

De esta manera, el monstruo digital es un monstruo siniestro, en el sentido de que es imposible de concretizar, de identificar plenamente; pero que, sin embargo, es capaz 
de ocasionar una serie de daños perceptibles, que dejan secuelas y generan un nivel de angustia que nubla lo cotidiano.

Pero la normalidad no solo se ve contaminada a partir de la presencia del doble: también se ve afectada porque todos esos procesos digitales que la protagonista ya ha asimilado a su mundo, de pronto, se ven truncos. Lola se va dando cuenta, aterrada, de que no puede ingresar a su cuenta para, finalmente, constatar que su cuenta ha sido totalmente usurpada. El nivel de angustia crece mientras la protagonista va comprobando la usurpación al seguir los pasos que le indica soporte técnico.

Es en ese momento cuando la normalidad de Lola ha sido totalmente contaminada por el monstruo: un monstruo que no solo se ve como ella, hace lo que ella hace y se atreve a ir más allá, sino que, además, le ha generado acaso el mayor miedo moderno: el miedo a no poder entrar a nuestra cuenta, a que la contraseña, de la nada, aparezca como incorrecta.

Cam nos muestra un mundo en el que, de pronto, los miedos ya no necesariamente pasan como en el cine de terror de toda la vida: a ser asesinados o atacados por una entidad que no nos deja tranquilos. Ahora la intranquilidad se debe, en un mundo donde la normalidad es digital, a que no podamos acceder a nuestra cuenta, a que de pronto veamos un monto que no reconocemos en nuestra tarjeta de crédito, a que un video de nosotros tomado por algún hacker circule en la web. La clonación, el revenge porn, el tráfico de contraseñas son miedos que hoy en día están en nuestro imaginario porque, justamente, rompen con la nueva normalidad, con aquello que hoy día podemos considerar como nuestra propia cotidianidad. Cam toma esos miedos y los alegoriza sobre la base del doppelgänger de Lola, un doble que usa las mismas herramientas y tiene el mismo conocimiento que cualquiera para hostigar a la protagonista, quien de pronto ve cómo su mayor terror se comienza a concretar. Un terror que no pasa por la muerte, la tortura o la violencia (por el contrario, esas son herramientas que Lola utiliza para ganar adeptos, popularidad y dinero): un terror causado por no poder ingresar a su cuenta, por quedarse log off. Un terror que responde al quiebre de la nueva normalidad digital.

\section{CONCLUSIONES}

Como señala el crítico David Ehrlich en su artículo para el sitio web Indiewire (2018), Cam es una película que trata del "horror existencial de quedarse afuera de su cuenta". En efecto, la película juega con el horror, entendiendo este como el género en el cual una entidad perturba lo cotidiano. Y, justamente, hoy en día, la cotidianidad consiste en vivir en el mundo virtual, en utilizar las herramientas que nos dan los medios digitales para desenvolvernos en nuestra vida diaria. 
Además, Cam explora los miedos que han traído los mundos digitales desde distintos frentes. Por un lado, establece una dicotomía entre mundo virtual y mundo real que afecta directamente a Lola: ella ha encontrado un refugio en el primero, mientras el segundo se convierte en un sitio incierto, incómodo y hasta violento. Por otro lado, le da una mirada al género del terror desde la posmodernidad: el horror hoy en día plantea una representación mucho más realista, sin censura, que la protagonista acepta y usa como una herramienta para generar mayores utilidades en su trabajo. Entre más violento, más rentable es el anárquico mundo de internet.

Pero la aparición de su doble (otro de los elementos recurrentes del cine de terror) viene a trastocar su cotidianidad, su tranquilidad: una doble que tiene su misma figura, su misma imagen, su mismo cuarto. El desconcierto que genera esa entidad y su origen no se podrían entender si no fuera por el hecho de que es un monstruo digital: la propia hibridez del medio, que es una mezcla de las características de otros medios, permite que ese monstruo pueda explicarse por distintas causas: una falla del sistema, un hacker, una duplicación. Todas esas opciones son una posibilidad para explicar lo que ocurre, y esa incertidumbre hace que la entidad sea difícil de vencer: no bastan un cazafantasmas, el disparo certero de un policía o una sesión de exorcismo para acabar con el mal.

Y acaso esa incertidumbre sea la que, en el día a día, vivimos con internet. Como todos podemos crear, todos tenemos el mínimo de conocimiento para usarlo, todos podemos también emplearlo para cometer algún hecho reprobable o delictivo. Cam utiliza elementos del cine de terror para, a través de ellos, ser una metáfora de los cambios que ha traído lo digital en nuestra vida: el mundo virtual, la competitividad, la violencia, la posibilidad de quedarnos afuera de nuestra cuenta. Y la violación de esa nueva cotidianidad es, quizá, lo más aterrador que puede ocurrir. El que veamos en la pantalla que nuestra contraseña no es válida es lo más espeluznante que nos puede pasar hoy en día, y Cam recurre al género del terror para explotar ese miedo.

\section{REFERENCIAS}

Bordwell, D. (2003). Arte cinematográfico. McGraw-Hill; Interamericana Editores.

Castells, M. (1999). La era de la información. Economía, sociedad y cultura. La sociedad red (vol. 1). Siglo xxı Editores.

Ehrlich, D. (19 de julio del 2018). Cam review: a brilliant Madeline Brewer anchors a Lynchian horror movie about a cam girl in crisis - Fantasia 2018. Indiewire. https://www.indiewire.com/2018/07/cam-review-daniel-goldhaber-madelinebrewer-fantasia-2018-1201985605/

Gledhill, C. (1999). The horror film. En P. Cook y M. Bernink (Ed.), The cinema book (pp. 194-204). British Film Institute. 
Goldhaber, D. (2018). Cam [película]. Divide/Conquer.

Gubern, R., y Prat, J. (1979). Las raíces del miedo. Antropología del cine de terror. Tusquets.

Imbert, G. (2010). Cine e imaginarios sociales. Cátedra.

Imbert, G. (2019). Crisis de valores en el cine posmoderno (más allá de los límites). Cátedra.

Meehan, P. (2017). The ghost of one's self, doppelgängers in mystery horror and science fiction film. McFarland \& Company, Inc., Publishers.

Perceval, J. M. (2015). Historia mundial de la comunicación. Cátedra.

Scolari, C. (2008). Hipermediaciones. Elementos para una teoría de la comunicación digital interactiva. Gedisa.

Waisbord, S. (2019). Communication. A post-discipline. Polity Press.

Wood, R. (Ed.). (2018). An introduction to the American horror film. En Robin Wood on the horror film. Collected essays and reviews (pp. 73-110). Wayne State University Press. 